\title{
The Role of Environmental Factors in the Aetiology of Social Anxiety Disorder: A Review of the Theoretical and Empirical Literature
}

\author{
Alice R. Norton' and Maree J. Abbott ${ }^{2}$ \\ I Brain and Mind Centre, The University of Sydney, New South Wales, Australia \\ ${ }^{2}$ Clinical Psychology Unit, School of Psychology, The University of Sydney, New South Wales, Australia
}

\begin{abstract}
Social anxiety disorder (SAD) is characterised by a marked and persistent fear of social/performance situations, and a number of key environmental factors have been implicated in the aetiology of the disorder. Hence, the current article reviews theoretical and empirical evidence linking the development of SAD with parenting factors, traumatic life events, and aversive social experiences. Specifically, research suggests that the risk of developing SAD is increased by over-controlling, critical and cold parenting, an insecure attachment style, aversive social/peer experiences, emotional maltreatment, and to a lesser extent other forms of childhood maltreatment and adversity. Moreover, these factors may lead to posttraumatic reactions, distorted negative self-imagery, and internalised shame-based schemas that subsequently maintain SAD symptomatology. However, further research is necessary to clarify the nature, interactions, and relative contributions of these factors. It is likely that SAD develops via a complex interplay of biological and environmental factors, and that multiple aetiological pathways underlie the development of the disorder.
\end{abstract}

Keywords: social anxiety, trauma, imagery, aetiology, environment

\section{The Aetiology of Social Anxiety Disorder}

Social anxiety disorder (SAD) involves persistent and excessive fear of negative evaluation or judgement in social situations (Diagnostic and Statistical Manual of Mental Disorders [5th ed.; DSM-5]; American Psychiatric Association [APA], 2013). In interpersonal and/or performance-based social situations, an individual fears that s/he will behave in a way that will be humiliating or embarrassing; hence, such situations are avoided or endured with intense anxiety. SAD is associated with difficulties across a range of life domains, and it has been proposed that the disorder may lie on a number of spectrums, including social fear and avoidance, body-focused concerns, affective dysfunction, and social deficits (Stein, Ono, Tajima, \& Muller, 2004). SAD typi-

76 cally has an early onset (median $=13$ years of age in Australia) and chronic course (McEvoy, Grove, \& Slade, 2011; Ruscio et al., 2008). In Australia, SAD has 12month and lifetime prevalence rates of $4.2 \%$ and $8.4 \%$ respectively, and close to $70 \%$ of individuals with SAD have experienced a comorbid disorder during their lifetime (Crome et al., 2015). SAD is associated with considerable suffering and functional

Address for correspondence: Alice Norton, Level 5 (M02F), 94 Mallett St, Camperdown, The University of Sydney NSW 2006, Australia. Email: alice.norton@sydney.edu.au 
impairment (e.g., relationships, employment), yet the majority of people with SAD do not seek treatment (Crome et al., 2015).

No clear pathway has been identified in the development of SAD; however, a range of factors have been proposed to increase risk of developing the disorder. Genetic, neurobiological, and temperamental factors have been implicated in the development of SAD (e.g., Kimbrel, 2008; Tillfors, 2004), with a recent meta-analysis of twin studies reporting heritability estimates of $41 \%$ across age groups (Scaini, Belotti, \& Ogliari, 2014), indicating that shared emotional vulnerability is significant in disorder development. However, environmental factors also appear to account for a substantial proportion of variance ( $54 \%$ for non-shared environmental factors across age groups; Scaini et al., 2014). Models of the aetiology of SAD propose that key environmental influences on the development of SAD include parenting factors, traumatic life events, and aversive social experiences (Beidel \& Turner, 2007; Elizabeth et al., 2006; Hudson \& Rapee, 2000; Lampe, 2009; Neal \& Edelmann, 2003; Ollendick \& HirshfeldBecker, 2002; Rapee \& Spence, 2004; Wong \& Rapee, 2015). Moreover, given that SAD typically develops in late childhood and early adolescence, the nature of early environmental factors is likely to be critical in understanding of the aetiology of the disorder and facilitating the development of more effective treatments (Wong \& Rapee, 2015).

\section{Aims and Methodology}

Given the theoretical and empirical significance of environmental factors in the aetiology of SAD, this paper aimed to review empirical evidence for the role of parenting factors, traumatic life events, and aversive social experiences in the development of SAD, including limitations of current research and suggested future directions. A comprehensive literature search was conducted among articles indexed in the PsycInfo, Medline, and PubMed. The keywords employed included: social anxiety, SAD, social phobia, aetiology, etiology, development, model, environmental, parenting, modelling, parental style, attachment, trauma, abuse, maltreatment, neglect, negative experiences, aversive experiences, emotional abuse, physical abuse, sexual abuse, social trauma, peers, victimisation, bullying, imagery, posttraumatic symptoms, and shame. Reference lists of relevant articles were also closely examined for additional papers.

\section{Parenting Factors}

There is evidence to suggest that parent-child interaction may be a predisposing factor that influences risk of developing SAD (Higa-McMillan \& Ebesutani, 2011). While a recent meta-analysis reported that parenting accounted for only $4 \%$ of the variance in child anxiety (McLeod, Wood, \& Weisz, 2007), this review was not specific to SAD. Moreover, the early age of disorder onset (McEvoy et al., 2011) suggests that parental factors may play a larger role in the development of SAD relative to other anxiety disorders (Bogels, van Oosten, Muris, \& Mulders, 2001). Ollendick and Hirshfeld-Becker (2002) propose that key parental influences on the development of SAD include behavioural modelling, parenting style, and attachment quality. While it appears that such factors are significant in the development of SAD, it remains unclear whether these parental behaviours occur in response to a child's temperament or anxious behaviours, are causal antecedents of social anxiety, or some interaction of the two (Wong \& Rapee, 2015). It is likely that these factors have a 
complex and reciprocal relationship, such that a child's anxious or inhibited behaviour may interact with parental factors in a way that amplifies socially anxious affective, cognitive, and behavioural patterns.

\section{Behavioural Modelling}

Observational learning and information transfer from parent to child regarding social concerns and social avoidance have been proposed to contribute to the development of SAD (Hudson \& Rapee, 2000). Parents of SAD children may model social concerns, express fears of negative evaluation, and catastrophise potential negative social outcomes. Such modelling may build a perception of social threat and an expectation that others may judge them negatively. Consistent with this theory, SAD individuals report that their parents tended to highlight the importance of other's opinions and emphasise the importance of appearance, (Bruch, 1989; Bruch \& Heimberg, 1994). However, there are no known observational studies to date that have documented specific modelling of social concerns among parents of SAD individuals.

Furthermore, SAD individuals are more likely to have anxious parents, who tend to be less socially active, more inhibited, and less engaged with their children (Bandelow et al., 2004; Festa \& Ginsburg, 2011; Knappe, Beesdo et al., 2009; Woodruff-Borden, Morrow, Bourland, \& Cambron, 2014). In this way, anxious parents may model social avoidance, restrict or prevent social engagement or opportunities for the development of social skills, and thus perpetuate a cycle of social fear (e.g., Bruch \& Heimberg, 1994; Caster, Inderbitzen, \& Hope, 1999).

A range of evidence suggests that SAD parents are more likely to model avoidant behaviour. For example, adults with SAD frequently report that their parents were more socially isolated and discouraged sociability both inside and outside of the family (Anhalt \& Morris, 2008; Bruch, 1989; Bruch \& Heimberg, 1994; Festa \& Ginsburg, 2011; Rapee \& Melville, 1997). Moreover, mothers of SAD adults report that they were more controlling of the socialisation experiences of their children (Rapee $\&$ Melville, 1997). Such modelling was demonstrated in a study by Barrett, Rapee, Dadds, and Ryan (1996), who found that anxious children were more likely to interpret ambiguous scenarios as threatening, and to adopt more avoidant coping strategies after discussion with their parents compared to non-anxious children (Barrett et al., 1996). The authors suggest that families may provide the context in which children learn to interpret and respond to situations as threatening, and that anxious cognitive and behavioural patterns may be modelled, supported, and reinforced by parents of anxious children.

\section{Parenting Style}

Parental over-control and over-protection have demonstrated a moderately consistent association with the development of anxiety disorders (Rapee \& Spence, 2004). Adults with SAD tend to perceive their parents as being over-controlling and restricting of their autonomy (e.g., Arrindell, Emmelkamp, Monsma, \& Brilman, 1983; Arrindell et al., 1989; Bandelow et al., 2004; Festa \& Ginsburg, 2011; Gulley, Oppenheimer, \& Hankin, 2014; Rapee \& Melville, 1997). While many of these studies have utilised retrospective self-report, there is some behavioural data to support these findings. For example, in further analyses of the study by Barrett and colleagues (1996), the authors found that parents of anxious children listened and agreed less with their child, indicating less support for autonomous thought and action (Dadds, Barrett, 
Rapee, \& Ryan, 1996). Moreover, Hudson and colleagues observed that mothers of anxious children were more intrusive and involved during a collaborative task or discussion of experiences involving negative affective states (Hudson \& Rapee, 2001, 2002; Hudson, Comer \& Kendall, 2008). Specific to social anxiety, two observational studies have found that parents of socially anxious children displayed more controlling behaviours during a challenging task with their children (Greco \& Morris, 2002; Rork \& Morris, 2009). Importantly, this relationship has been supported by a longitudinal study in which higher observed maternal over-control at 7 years of age predicted increased symptoms of social anxiety and higher rates of SAD diagnosis during adolescence (Lewis-Morrarty et al., 2012). Closely related to over-control, $\mathrm{SAD}$ individuals frequently report that their parents were over-protective (e.g., Arrindell et al., 1983; Knappe, Lieb et al., 2009; Knappe, Beesdo-Baum, Fehm, Leib, \& Wittchen, 2012; Parker, 1979; Spokas \& Heimberg, 2009; Taylor \& Alden, 2006). Indeed, an over-protective parental style has also been associated with increased risk for the development of SAD among adolescents who were still living with their parents (Lieb et al., 2000).

Over-controlling and over-protective parenting may restrict the development of self-efficacy and social autonomy, in addition to reducing opportunities for the development of social skills. Such parenting also communicates to a child that they lack the capacity to cope with challenging situations and require protection from a dangerous world (Hudson \& Rapee, 2000). In contrast, challenging paternal behaviour (in which a child is playfully encouraged to push their limits) appears to protect against the development of SAD in 4-year-olds (Majdandzic, Moller, de Vente, Bogels, \& van den Boom, 2014). However, not all studies have found a link between SAD and over-controlling or over-protective parenting, suggesting that this is a possible but not necessary factor in the development of SAD (e.g., Arkinsola \& Udoka, 2013; Bogels et al., 2001; Vreeke, Muris, Mayer, Huijding, \& Rapee, 2013).

In addition, some SAD individuals recall their parents being less warm, as well as more rejecting, critical, and shaming, in comparison to healthy controls (Arrindel et al., 1983; Bandelow et al., 2004; Bruch \& Heimberg, 1994), and these parental attributes have been associated with higher social anxiety symptoms (Anhalt \& Morris, 2008; Caster et al., 1999; Festa \& Ginsburg, 2011; Knappe et al., 2012; Knappe, Lieb et al., 2009; Mothander \& Wang, 2014; Rudoph \& Zimmer-Gembeck, 2014; Spokas $\&$ Heimberg, 2009). Consistent with these findings, an observational study found that parents of SAD children provided less positive feedback and more negative feedback compared to parents of non-anxious children during a collaborative task (Hummell \& Gross, 2001), and lower parental emotional warmth has been found to predict higher persistence of SAD (Knappe, Beedso et al., 2009). Indeed, it is possible that frequent exposure to negative feedback within the family may lead some children to become hypervigilent and preoccupied by the perceived likelihood of negative social evaluation. While these factors are not consistently related to SAD (e.g., Rork \& Morris, 2009), they may be more pronounced where the parent has a history of an anxiety disorder themselves (e.g., Lieb et al., 2000), or in combination with other aetiological factors, whether biological or environmental.

\section{Attachment}

An insecure attachment style has been associated various types of psychopathology (DeKlyen \& Greenberg, 2008), including social anxiety during childhood and 
adulthood. Securely attached individuals are more readily able to engage in positive relationships with peers and join social activities, whereas insecure individuals have weaker social and emotional competence, and thus tend to be less socially engaged, positive and popular at school, as well as more socially anxious in later childhood (BarHaim, Dan, Eshel, \& Sagi-Schartz, 2007; Bohlin, Hagekull, \& Rydell, 2000; Brumariu \& Kerns, 2010; Kerns \& Brumariu, 2014). Specifically, an anxious-ambivalent attachment style has been most commonly linked to later development of anxiety disorders, including SAD (Kerns \& Brumariu, 2014; Warren, Huston, Egeland, \& Sroufe, 1997). Anxious-ambivalent attachment is linked to erratic and unpredictable parenting, which is consistent with the variety of reported parenting styles associated with SAD (see Parenting Style). It may be that it is a variable and inconsistent style of parenting, rather than (or in combination with) a particular style of parenting that most increase one's risk of developing SAD.

Warren and colleagues (1997) reported that anxious-ambivalent (but not anxiousavoidant) attachment in infants predicted increased risk for the development of anxiety disorders in adolescents 16 years later, with $38 \%$ of these individuals developing $\mathrm{SAD}$. The authors suggest that anxiety arising from the uncertain availability of an attachment figure may be internalised and lead to difficulties in coping with the anxiety of ongoing developmental challenges (Warren et al., 1997). Furthermore, prospective studies indicate that an anxious-ambivalent attachment style may increase specific risk of developing SAD (Bar-Haim et al., 2007; Brumariu \& Kerns, 2010). Inconsistency within the caregiver-infant relationship and consequent anxiety regarding the availability of attachment figures experienced by anxious-ambivalent infants may lead to distrust in subsequent social relationships, and an experience of persistent threat of social exclusion or rejection (Vertue, 2003). Correspondingly, SAD adults most commonly demonstrate an anxious-ambivalent (preoccupied) attachment style, which is associated with discomfort in close relationships, difficulty trusting or depending on others, and greater anxiety at the prospect of rejection or abandonment compared to controls (Eikenaes, Pederson, \& Wilberg, 2015; Eng, Heimberg, Hart, Schneier, \& Liebowitz, 2001).

Interestingly, two studies have found children with a disorganised attachment style report being more shy and socially anxious compared to controls, and to report higher rates of SAD (Borelli, David, Crowley, \& Mayes, 2010; Brumariu \& Kerns, 2010). However, both studies were cross-sectional, and no known longitudinal or prospective studies to date have demonstrated this relationship. Nonetheless, these findings are consistent with attachment theory, as children with disorganised attachment are considered to perceive other's behaviour as unpredictable and frightening (Borelli et al., 2010). Indeed, Kerns and Brumariu (2014) suggest that disorganised children are likely to be at greatest risk of developing anxiety as they lack access to a secure base, having experienced caregivers who are unpredictable, unavailable, or punitive.

\section{Negative and Traumatic Life Experiences}

Traumatic or difficult life experiences are another factor that has been linked to the development of SAD. While negative experiences may be precipitating factors that immediately precede SAD onset (Higa-McMillan \& Ebesutani, 2011), the weight of theory and empirical evidence suggests that such events are predisposing factors that increase risk of developing many forms of psychopathology, including 
(but not uniquely) SAD (e.g., Kessler, Davis, \& Kendler, 1997; Kimbrel, 2008; Rapee \& Spence, 2004; Wong \& Rapee, 2015). Indeed, SAD has been associated with substantially less childhood abuse and fewer adverse life events compared to other disorders, such as major depressive disorder or panic disorder (Kessler et al., 1997; Tiet et al., 2001; Safren, Gershuny, Marzol, Otto, \& Poll, 2002). Nonetheless, Simon et al. (2009) reported that $70 \%$ of a sample of SAD individuals $(N=72)$ met threshold criteria for at least one type of childhood maltreatment, and Rosellini and colleagues (2013) reported that $78.8 \%$ of a SAD sample $(N=210)$ could identify the presence of an acute or chronic stressor around the time of SAD onset. Wong and Rapee (2015) suggest that negative experiences are likely to be of particular import in the development of SAD if they are social or relational in nature (e.g., parental marital discord, emotional, sexual, or physical abuse). Moreover, chronic adversity during sensitive developmental periods may increase risk of developing SAD via changes to the amygdala (Pechtel, Lyons-Ruth, Anderson, \& Teicher, 2014) or enhanced cortisol reactivity to stress (Elzinga, Spinhoven, Berretty, de Jong, \& Roelofs, 2010).

\section{Emotional Abuse and Neglect}

Compared to other key trauma domains (i.e., sexual abuse and physical abuse/neglect), SAD has been most strongly related to childhood emotional abuse and neglect (Bandelow et al., 2004; Bruce, Heimberg, Blanco, Schneier, \& Liebowitz, 2012; Gibb, Chelminski, \& Zimmerman, 2007; Iffland, Sansen, Catani, \& Neuner, 2012; Kuo, Goldin, Werner, Heimberg, \& Gross, 2011; Pohjavaara, 2004; Simon et al., 2009; Spinhoven et al., 2010). This is consistent with reports that parents of SAD individuals are over-controlling, less warm, and more rejecting (see Parenting Style). Among SAD individuals, emotional maltreatment has been associated with greater severity of social anxiety symptomatology and related disability, higher trait anxiety and depression, as well as poorer functioning, resilience, quality of life, and self-esteem (Bruce, Heimberg, Blanco, Schneier, \& Liebowitz, 2012; Bruce, Heimberg, Goldin, \& Gross, 2013; Gibb, Chelminski, \& Zimmerman, 2007; Iffland et al., 2012; Kuo et al., 2011; Simon et al., 2009). Furthermore, emotional abuse has been found to increase risk of peer rejection, which is frequently a key precipitant for SAD onset (see section entitled Emotional Abuse and Neglect in this article; Lev-Wiesel \& Sternberg, 2012).

Some studies have found emotional abuse and neglect to be more strongly related to SAD than to physical or sexual abuse (Gibb et al., 2007; Iffland et al., 2012; Kuo et al., 2011). In one study, emotional maltreatment was retrospectively reported by $56 \%(n=58)$ of SAD individuals, compared to 30\% $(n=29)$ reporting physical abuse and 19\% $(n=18)$ reporting sexual abuse (Simon et al., 2009). Furthermore, emotional maltreatment by parents has been found to mediate the impact of physical and sexual maltreatment on social anxiety symptoms (Iffland et al., 2012). Whereas other disorders tend to be equally associated with multiple forms of early maltreatment (e.g., posttraumatic stress disorder with emotional, physical, and sexual abuse), it has been suggested at SAD may be specifically related to emotional abuse rather than early trauma per se (Gibb et al., 2007). Nonetheless, emotional maltreatment has also been frequently linked to other psychopathology (e.g., major depressive disorder; Gibb et al., 2007), suggesting that it does not solely or specifically increase the risk of developing SAD, and may therefore be a more distal causal factor. 


\section{Sexual and Physical Abuse}

While SAD appears to be most strongly associated with emotional abuse and/or neglect, sexual abuse has also been found to heighten risk of developing the disorder and increase severity of social anxiety symptomatology, especially among females (Bandelow et al., 2004; Bruce et al., 2013; Chartier, Walker, \& Stein, 2001; Cougle, Timpano, Sachs-Ericsson, Keough, \& Riccardi, 2010; Dinwiddie et al., 2000; Feerick \& Snow, 2005; Gibb et al., 2007; Magee, 1999; Nelson et al., 2002; Spinhoven et al., 2010). For example, the U.S. National Comorbidity Survey $(N=8,098)$ indicated that those who had experienced molestation or rape were significantly more likely to report SAD (odds ratios ranged from 1.67 to 1.77; Kessler, Davis, \& Kendler, 1997). In addition, younger age of sexual abuse onset and greater psychological pressure to participate has been associated with greater social avoidance and distress, as has actual or attempted intercourse (Feerick \& Snow, 2005).

Physical abuse/violence and neglect have also been demonstrated to increase risk of developing SAD and to predict greater social anxiety symptom severity (Bandelow et al., 2004; Binelli et al., 2012; Bruce et al., 2012; Chartier et al., 2001; Gibb et al., 2007; Magee, 1999; Pohjavaara, 2004; Spinhoven et al., 2010). Indeed, one study found that family violence (but not emotional, physical or sexual abuse) predicted greater social anxiety among Spanish university students (Binelli et al., 2012), which is consistent with findings that having an aggressive mother or father may increase the risk of developing SAD (odds ratios ranged from 1.34 to 1.77; Kessler et al., 1997). Domestic physical abuse also increases the risk of social peer rejection, which is frequently a precipitating factor in SAD (see section, Negative and Traumatic Life Experiences; Lev-Wiesel \& Sternberg, 2012), and this relationship may be mediated by social withdrawal or other coping efforts. Nonetheless, both sexual and physical abuse have also been linked to other disorders (e.g., panic disorder and posttraumatic stress disorder; Cougle et al., 2010; Stein et al., 1996), indicating that these traumatic experiences do not confer specific risk for SAD.

\section{Other Negative Life Events}

Other negative events that are social in nature have also been associated with the development of SAD. Compared to healthy controls, SAD has been associated with more frequent reports of death of a parent(s), or other means of separation from parents (Bandelow et al., 2004; Kessler et al., 1997), family conflict, including parental marital discord (Bandelow et al., 2004; Chartier et al., 2001), parental divorce or separation (Kessler et al., 1997), lack of close relationship with an adult (Chartier et al., 2001), and having to start a new school (Tiet et al., 2001). Furthermore, SAD individuals were more likely to report having a parent or family member with significant psychopathology, including an anxiety, mood, or substance use disorder (Chartier et al., 2001; Kessler et al., 1997; Lieb et al., 2000; Tiet et al., 2001). Such negative relational experiences may be interpreted as indicating that others are dangerous, not trustworthy, or likely to humiliate, reject or ostracise, thereby heightening perceived social threat. However, these experiences do not appear to confer specific risk for SAD and are also linked to other psychopathology (e.g., parental separation and family conflict are associated with both conduct disorder and major depressive disorder; Tiet et al., 2001). 


\section{Aversive Social/Peer Experiences}

Social and peer-related negative and traumatic events (e.g., bullying, humiliation, ostracism) are considered to be direct conditioning experiences associated with the onset and development of SAD symptomatology, including increased distress and avoidance related to social situations (Higa-McMillan \& Ebesultani, 2011; Ollendick \& Hirshfeld-Becker, 2002; Rapee \& Spence, 2004; Wong \& Rapee, 2015). Accordingly, peer victimisation is more strongly associated with SAD compared to other anxiety disorders (Cohen \& Kendall, 2015; McCabe, Antony, Summerfeldt, Liss, \& Swinson, 2003) or depression (Ranta et al., 2009), and several studies have found that a substantial proportion of SAD individuals retrospectively report direct traumatic social experiences (e.g., Beidel, Turner \& Morris, 1999; Hofmann, Ehlers, \& Roth, 1995; Ost \& Hugdahl, 1981; Sansen, Iffland, \& Neuner, 2015; Stemberger, Turner, Beidel, \& Calhoun, 1995). For example, an early study found that $58 \%$ of a SAD sample ascribed disorder onset to a traumatic conditioning experience (Öst, 1987). Indeed, many SAD adults indicate that such an event was associated with the onset or exacerbation of the disorder (Hackmann, Clark, \& McManus, 2000; McCabe et al., 2003; Rosellini, Rutter, Bourgeois, Emmert-Aronson, \& Brown, 2013).

Aversive social conditioning experiences may be discrete humiliating events, but are often repetitive, cumulative experiences of chronic social trauma that threaten the basic human need for acceptance and can act as experiences that confirm already developing social threat fears and beliefs (Baumeister \& Leary, 1995; Tillfors et al., 2012). Furthermore, traumatic conditioning may occur vicariously via witnessing or hearing about the humiliating social experience of another (Beidel \& Turner, 2007; Ollendick \& Hirshfeld-Becker, 2002). Peer victimisation has been found to predict increased social anxiety over time, and may include overt victimisation (e.g., physical or verbal aggression), relational victimisation (e.g., psychological bullying, friendship withdrawal or exclusion, peer neglect, or rejection), or damage to reputation (e.g., spreading rumours; Siegel et al., 2009). However, there is evidence to suggest that relational victimisation may be the strongest risk factor for SAD (e.g., Landoll, La Greca, Lai, Chan, \& Herge, 2015; Storch et al., 2005).

\section{Relational Victimisation}

Relational victimisation involves the use of relational assaults to harm a peer (e.g., via exclusion from a social group, or emotional bullying; Seigel et al., 2009; Storch et al., 2005). In cross-sectional studies, social anxiety and SAD diagnosis are consistently positively associated with higher levels of relational victimisation and social exclusion, fewer friends and difficulty making new friends, less peer acceptance and more negative interactions in close friendships, as well as more social avoidance and withdrawal (Boulton, 2013; Craig, 1998; Demsey \& Storch, 2008; Erath et al., 2007; Greco \& Morris, 2005; Iffland, Sansen, Cantani, \& Neuner, 2012; La Greca \& Harrison, 2005; Landoll et al., 2015; Ranta et al., 2009; Rapee \& Melville, 1997; Scharfstein, Alfano, Beidel, \& Wong, 2011; Storch, Brassard, \& Masia-Werner, 2003; Storch \& MasiaWarner, 2004; Yen et al., 2014). Conversely, lower levels of social anxiety are associated with stronger social support, acceptance, and peer validation, suggesting that these factors may buffer excessive fears of social scrutiny and negative judgement (Festa $\&$ Ginsburg, 2011). Prospective studies support these associations, demonstrating that relational victimisation, exclusion, and lower peer acceptance predict greater social anxiety and likelihood of a SAD diagnosis over time, and may have greater impact 
than overt victimisation (Seigel, La Greca, \& Harrison, 2009; Teachman \& Allen, 2007; Tillfors, Persson, Willen, \& Burk, 2012; Storch, Masia-Werner, Crisp, \& Klein, 2005), especially among girls (Ranta, Kaltiala-Heino, Frojd, \& Marttunen, 2013).

While a number of studies demonstrate that social anxiety is associated with active relational victimisation, SAD may also be associated with social neglect and isolation, such that some socially anxious children may simply be overlooked or ignored rather than actively disliked, manipulated, or rejected (Beidel \& Turner, 2007; Hudson \& Rapee, 2000). Furthermore, the experience of social failure associated with social neglect may exacerbate existing tendencies for self-isolation, generating a vicious cycle (Adalbjarnardottir, 1995; Beidel \& Turner, 2007; Hudson \& Rapee, 2000; Rubin \& Mills, 1988).

\section{Overt Victimisation}

Perhaps unsurprisingly, overt victimisation (e.g., physical or verbal assault) also appears to be associated positively with fears of negative evaluation, social avoidance, and the development of SAD - albeit less strongly than relational victimisation (Storch et al., 2003; Storch \& Masia-Werner, 2004). Thus, cross-sectional studies demonstrate that SAD diagnosis and higher social anxiety levels are associated with more negative peer interactions, verbal aggression, and direct victimisation (Craig, 1998; Erath, Flanagan, \& Bierman, 2007; Landoll et al., 2015; Ranta, Kaltiala-Heino, Pelkonen, \& Marttunen, 2009; Yen et al., 2014). Adolescents with SAD report more frequent overt victimisation than those without SAD (Gren-Landell, Aho, Andersson, \& Svedin, 2011), and adults who report overt bullying in childhood demonstrate higher prevalence of SAD (48.1\%) compared to those who did not report childhood bullying (26.4\%) (Gladstone, Parker, \& Malhi, 2006). Importantly, prospective studies also demonstrate that overt victimisation (physical or verbal aggression) increases risk of developing SAD and predicts greater social anxiety symptomatology over time (Loukas $\&$ Pasch, 2013; Storch et al., 2005; Vernberg, Abwender, Ewell, \& Beery, 1992), especially among boys (Marteinsdottir, Svensson, Svedberg, Anderberg, \& von Knorring, 2007; Ranta, Kaltiala-Heino, Frojd, \& Marttunen, 2013; Storch et al., 2003).

In addition, social anxiety appears to be particularly associated with verbal bullying (e.g., teasing or name calling). Thus, SAD adults are more likely to report a history of frequent teasing compared to individuals with panic disorder or obsessive-compulsive disorder (McCabe, Miller, Laugesen, Antony, \& Young, 2010), and a history of childhood teasing has been associated with greater social anxiety symptomatology (McCabe et al., 2010; Roth, Coles, \& Heimberg, 2002). Indeed, one study found that $92 \%$ of a sample of adults with SAD reported experiencing severe teasing in childhood (McCabe, Antony, Summerfeldt, Liss, \& Swinson, 2003). Furthermore, there is some evidence to suggest that cyber victimisation (i.e., overt victimisation via the internet or other forms of electronic media) is also associated with social anxiety (Landoll et al., 2015). However, findings are preliminary and suggest that relational victimisation remains a stronger predictor (Landoll et al., 2015).

\section{The Relationship of Aversive Social Experiences and SAD}

A number of studies suggest that social anxiety has a bidirectional relationship with social victimisation and rejection (e.g., Blöte, Bokhorst, Miers, \& Westenberg, 2012; Gazelle et al. 2005; Ranta et al., 2013; Siegel et al., 2009; Tillfors et al., 2012). This appears to be a vicious feedback cycle in which socially anxious individuals are more 
likely to be rejected or victimised (potentially due to poorer social performance; Blöte, Miers, \& Westenberg, 2015; Greco \& Morris, 2005), which in turn increases social threat and avoidance, leading to further rejection and victimisation (e.g., Pabian $\&$ Vandebosch, 2015). Furthermore, socially anxious children are more likely to experience commonplace social events as distressing or traumatic, thereby increasing their anxiety. For example, Beidel et al. (1999) described the most distressing events reported by SAD children as having to perform in front of others, being asked to answer a question by their teacher, being spoken to by a popular kid, and having to talk to someone on the telephone.

Interestingly, socially aversive experiences are also reported by individuals without SAD (Stemberger et al., 1995), and not all SAD individuals recall discrete socially traumatic events (Ost, 1987), suggesting that this is not a sufficient or necessary cause for the disorder. It is likely that SAD results from a complex interaction of such conditioning experiences, with biological factors, cognitive factors, parenting factors, and other negative experiences (Beidel \& Turner, 2007). For example, coping style has been found to moderate the relationship between peer victimisation and social anxiety (Boulton, 2013), and self-esteem has been found to partially mediate the association of peer relationships with social anxiety among adolescents (Bosacki, Dane, Marini, $\&$ YLC-CURA, 2007), consistent with the negative and unstable self-concept shown in SAD (Wilson \& Rapee, 2006).

\section{Posttraumatic Symptomatology and Imagery in the Aetiology of SAD}

Aversive social/peer experiences may be experienced as traumatic, and thus have been found to trigger posttraumatic symptoms among SAD individuals, including intrusive re-experiencing, avoidance, negative alterations in cognitions and mood, and hyperarousal symptoms (Carleton, Pelso, Collimore \& Asmundson, 2011; Erwin, Heimberg, Marx, \& Franklin, 2006). Erwin et al. (2006) found that a third of SAD individuals in their sample would have met criteria for Diagnostic and Statistical Manual of Mental Disorders (4th ed., text rev.; APA, 2000) posttraumatic stress disorder (PTSD) if the socially traumatic event satisfied criterion A (witnessing or experiencing death, serious injury or threat to one's own or another's physical integrity). In contrast to controls, SAD patients in this study reported reacting to memories of past socially aversive events with hyperarousal and avoidance (Erwin et al., 2006). SAD patients also endorsed significant re-experiencing symptoms in response to memories of socially traumatic events (though no more than controls), and the authors suggest that these symptoms may be 'distorted recollection of the past event, potentially contributing to distorted beliefs and interfering with the processing of socially stressful events' (Erwin et al., 2006, p. 909).

Moreover, there is an increasing body of literature suggesting that negative selfimagery plays a key role in the development and maintenance of SAD and that such imagery may be rooted in experiences of social trauma and threatened social belongingness (Clark \& Wells, 1995; Hirsch, Clark, Mathews, Williams, \& Morrison, 2006; Rapee \& Heimberg, 1997; Sansen et al., 2015; Schreiber \& Steil, 2013). Negative self-imagery appears to maintain social anxiety by facilitating and reinforcing negative interpretations of ambiguous social information (Hirsch, Clark, \& Mathews, 2006), increasing access to a negative working model of the self (Hulme, Hirsch, \& Stopa, 2012), and inhibiting retrieval of positive/realistic imagery, memories, and working 
models of the self (e.g., Hirsch et al., 2005; Hulme et al., 2012; Stopa \& Jenkins, 2007). Furthermore, utilising attentional resources to focus on negative self-imagery prevents SAD individuals from noticing neutral or positive feedback, or that their feared outcome may not be occurring. Hence, these processing biases prevent disconfirmation of feared social outcomes and impede updating of negative self-images with more realistic 'pictures' based on benign or positive experiences, or lessening the affective response associated with negative images, thereby maintaining social anxiety (Wild, 2009). Finally, focus on negative self-referent imagery increases anxiety and engagement in safety behaviours, thereby undermining social performance and increasing the actual and perceived likelihood of negative feedback (e.g., Hirsch, Meynen, \& Clark, 2004; Hirsch, Clark, Mathews, \& Williams, 2003).

Importantly, Hackmann et al. (2000) found that negative, distorted self-imagery experienced by SAD individuals tends to be linked in theme and content to earlier socially traumatic or aversive events (e.g., teasing, rejection) and that these events cluster around the onset or exacerbation of social anxiety symptoms. Such aversive social events in formative years appear to be laid down in memory and incorporate any negative meanings or catastrophic interpretations made at the time (Hirsch, Clark, $\&$ Matthews, 2006). The ensuing negative distorted self-images that are triggered by and recur in social situations (Hackmann, Surawy, \& Clark, 1998) may be considered comparable to intrusive re-experiencing symptomatology characteristic of PTSD (Erwin et al., 2006). Furthermore, recent research has yielded very strong treatment outcomes for SAD using imagery rescripting interventions that aim to update traumatic memories for SAD (e.g., Lee \& Kwon, 2013; Nilsson, Lundh, \& Viborg, 2012; Norton \& Abbott, 2016; Reimer \& Moscovitch, 2015; Wild, Hackmann, \& Clark, 2008), suggesting that such memories and associated intrusive imagery may be key precipitating and maintaining factors for the disorder.

\section{SAD as a Shame-Based Disorder}

Shame is a self-conscious emotion in which the individual experiences their global self as defective, thus wishes to hide, disappear, or die (Lewis, 2008), and has been defined as 'an intensely painful feeling or experience of believing we are flawed and therefore unworthy of acceptance and belonging' (Brown, 2006, p. 45). Despite being conceptually distinct, there is clear overlap between social anxiety and shame (Gilbert, 2000, 2014), and a number of studies have demonstrated a correlation between these constructs (e.g., Fergus, Valentiner, McGrath, \& Jencius, 2010; Gilbert, 2000; Hedman, Strom, Stunkel, \& Mortberg, 2013; Matos, Pinto-Gouveia, \& Gilbert, 2013). Indeed, while SAD is classified as an anxiety disorder, it is arguable that shame is as central as anxiety to the experience of individuals with severe social anxiety, and thus their condition may also be conceptualised as a shame disorder (Herman, 2011). Social anxiety appears to be strongly associated with internal shame, involving internalised negative judgments of oneself as undesirable, deficient, inferior, inadequate, weak, disgusting, or bad (Matos et al., 2013), but has also been linked to external shame (concern that one will be judged negatively for appearing this way in the eyes of others; Gilbert, 2014). Furthermore, it is plausible that the aetiological factors reviewed above (negative parenting, difficult life events, aversive social experiences) may influence the development of SAD via the internalisation of shame-based cognitive and affective states. 
Theory and empirical evidence indicates that severe and/or chronic experiences of being abused, rejected, criticised, and shamed during childhood (e.g., via social exclusion, verbal bullying, emotional abuse, punitive or unpredictable parenting) may lead to an internalised negative representation of the self, and thus an increased tendency toward experiencing shame (Claesson \& Sohlberg, 2002; Pinto-Gouveia \& Matos, 2011; Gilbert, 2003; Gilbert, Allan, \& Goss, 1996; Lewis, 2008; Matos et al., 2013; Stuewig \& McCloskey, 2005). Internal, stable, global attributions of these negative early experiences are argued to be stored as autobiographical experiences that become the foundation for subsequent self-related beliefs and behaviours (Gilbert, 2003). For example, a child who experiences frequent harsh criticism from their parents is likely to encode emotionally textured experiences of having elicited criticism from others and being treated as bad, and therefore comes to believe 'I am bad'(Gilbert, 2003). Similarly, a child who is excluded by peers is likely to encode emotionally textured experiences of having elicited exclusion from others and being treated as undesirable, and thus comes to internalise the belief that 'I am undesirable' (Gilbert, 2003). In this way, such experiences may be internalised as global evaluations of the self as undesirable, inferior, inadequate, weak, disgusting, or bad. These shame-based schemas (i.e., self-perpetuating dysfunctional cognitive-affective structures; Young, 1999) are frequently found among SAD individuals (e.g., Calvete, Orue, \& Hankin, 2013; Pinto-Gouveia, Castilho, Galhardo, \& Cunha, 2006), and are readily reactivated by social experiences (Lee, Scragg, \& Turner, 2001). Furthermore, the negative self-imagery described by SAD individuals frequently demonstrates shame-based as well as fear-based themes, and is rooted in shaming social experiences (Hackmann et al., 2000). This is consistent with findings that memories of shaming experiences may be encoded with the features of trauma memories (e.g., intrusion, affective avoidance, distorted/fragmented cognitive processes, hyperarousal; Matos \& Pinto-Gouseia, 2010) and that such memories can become a central reference point for personal narrative and self-identity (Pinto-Gouveia \& Matos, 2011).

While research has linked greater shame-proneness with negative parenting practices (e.g., Claesson \& Sohlberg, 2002; Webb, Heisler, Call, Chickering, \& Colburn, 2007), insecure attachment (e.g., Lopez et al., 1997), negative life experiences (e.g., Stuewig \& McCloskey, 2005), and social anxiety (e.g., Fergus et al., 2010), only one known study to date has specifically investigated the relationship between negative early life experiences, shame, and the development of SAD. Thus, Shahar, Doron, and Szepsenwol (2014) found that shame and self-criticism mediated the relationship between emotional abuse (but not neglect) and social anxiety symptomatology. Shahar et al. (2014) suggest that early emotional maltreatment may be internalised as a 'shame-based cognitive-affective schema' (p. 1), which is characterised by a global experience of the self as inadequate. The authors argue that self-criticism may also be adopted as a defensive strategy to protect against exposure of perceived flaws and deficiencies in the self, as well facilitating avoidance of the distress associated with reactivated shame states. These findings provide preliminary evidence for the crucial role of shame in the aetiology and maintenance of SAD.

\section{Limitations of Previous Studies}

There are a number of limitations in the literature on environmental factors in the aetiology of SAD. Critically, studies to date have been largely retrospective, self-report, and cross-sectional, and there may be bias in the subjective reports of 
anxious individuals often made many years after the events. Furthermore, most studies have explored the relationship between SAD and each key environmental factor individually; thus, the complex interplay, relative impact, and chronology of such factors remains relatively unexplored. Additionally, many studies report on childhood anxiety, rather than SAD specifically.

Moreover, while a range of negative experiences in childhood (e.g., emotional, physical, sexual maltreatment) have been considered possible precipitating factors for SAD, many theorists suggest that such negative life events increase an individual's predisposition toward developing psychopathology more generally (e.g., via development of negative beliefs about self or others) rather than rather than being specific to SAD (e.g., Rapee \& Spence, 2004). Thus, the specific or general impact of non-peer childhood trauma in the development of SAD remains unclear. Furthermore, no study has yet explored the impact of caregiver response to childhood abuse (e.g., management of abusive situation, support available to the child). Response to trauma is a strong predictor of posttraumatic symptoms (Lieberman, Chu, van Horn \& Harris, 2011), and hence may mediate the impact of negative life events on subsequent SAD development.

In addition, recent studies have suggested that socially traumatic experiences and their sequelae (e.g., negative distorted self-imagery) may be critical precipitating and maintaining factors in SAD (e.g., Erwin et al., 2006). However, only two studies (Carlton et al., 2011; Erwin et al., 2006) have demonstrated significant levels of posttraumatic symptomatology in response to socially aversive experiences, and these findings were based on DSM-IV rather than DSM-5 criteria for PTSD. Furthermore, the relation of aversive social experiences to the development of negative distorted self-imagery (a key maintaining factor in SAD; Clark \& Wells, 1995) requires clarification. Finally, only one known study to date has explored the role of internalised shame from early negative experiences in the development of SAD, and the possibility of a shame-based model of SAD has not been considered.

\section{Summary and Future Research Implications}

The above reviewed literature implicates a number of key environmental factors in the aetiology of SAD. Specifically, theory and research suggests that the risk of developing $\mathrm{SAD}$ is increased by over-controlling, critical and cold parenting, insecure (anxiousambivalent) attachment, emotional maltreatment, and to a lesser extent, physical and sexual maltreatment, and other relational adversities in childhood, as well as aversive social/peer experiences (especially relational victimisation). Moreover, these factors may lead to posttraumatic reactions, distorted negative self-imagery, and internalised shame-based schemas. However, understanding of the nature, interactions and relative contributions of these factors remains unclear. Moreover, it is likely that SAD develops via a complex interplay of biological and environmental factors, and that there are multiple and diverse pathways to the development of the disorder. Indeed, while environmental factors may serve as risk factors that increase the likelihood of developing SAD, they do not directly cause the disorder, and no single risk factor is sufficient or necessary to the development of SAD.

Future research would benefit significantly from the use of longitudinal prospective studies, greater utilisation of objective observational measures rather than subjective self-report, and assessment of the interplay of the range of environmental risk factors for SAD. Greater study of parenting factors and negative life events specific to $\mathrm{SAD}$ is also required. In particular, further investigation is required to understand 
whether particular traumatic life events increase risk for general psychopathology, or SAD specifically — or the conditions under which either may be the case. Furthermore, the impact of aversive peer experiences on posttraumatic symptomatology (including negative self-imagery) and their role in the maintenance of SAD requires further exploration, including the value of trauma-based interventions for the disorder (e.g., imagery rescripting; Wild et al., 2008). Additionally, as not all SAD individuals report a socially traumatic event associated with onset of the disorder, the role of other precipitating environmental factors warrants investigation. Finally, the role of shame in the development and maintenance of SAD is significantly understudied, and the conceptualisation of SAD as a shame-based disorder is deserving of consideration. Nonetheless, it remains likely that multiple aetiological pathways underlie the development of SAD.

\section{References}

Adalbjarnardottir, S. (1995). How schoolchildren propose to negotiate: The role of social withdrawal, social anxiety, and locus of control. Child Development, 66, 1739-1751.

American Psychiatric Association (APA). (2000). Diagnostic and statistical manual of mental disorders (4th ed., text rev.). Washington, DC: Author.

American Psychiatric Association (APA). (2013). Diagnostic and statistical manual of mental disorders (5th ed.). Washington, DC: Author.

Anhalt, K., \& Morris, T. (2008). Parenting characteristics associated with anxiety and depression: A multivariate approach. Journal of Early and Intensive Behavior Intervention, 5, 122-137.

Arkinsola, E., \& Udoka, P. (2013). Parental influence on social anxiety in children and adolescents: Its assessment and management using psychodrama. Psychology, 4, 246-253.

Arrindell, W., Emmelkamp, P., Monsma, A., \& Brilman, E. (1983). The role of perceived parental rearing practices in the aetiology of phobic disorders: A controlled study. The British Journal of Psychiatry, 143, 183-187.

Arrindell, W., Kwee, M.G., Methorst, G., van der Ende, J., Pol, E., \& Moritz, B. (1989). Perceived parental rearing styles of agoraphobic and socially phobic in-patients. British Journal of Psychiatry, $155,526-535$.

Bandelow, B., Torrente, C.A., Wedekind, D., Broocks, A., Hajak, G., \& Rüther, E. (2004). Early traumatic life events, parental rearing styles, family history of mental disorders, and birth risk factors in patients with social disorder. European Archives of Psychiatry and Clinical Neuroscience, 254, 397-405.

Bar-Haim, Y., Dan, O., Eshel, Y., \& Sagi-Schartz, A. (2007). Predicting children's anxiety from early attachment relationships. Journal of Anxiety Disorders, 21, 1061-1068.

Barrett, P.M., Rapee, R., Dadds, M., \& Ryan, S. (1996). Family enhancement of cognitive style in anxious and aggressive children. Journal of Abnormal Child Psychology, 24, 187-203.

Baumeister, R., \& Leary, M. (1995). The need to belong: Desire for interpersonal attachments as a fundamental human motivation. Psychological Bulletin, 117(3), 497-529.

Beidel, D.C., \& Turner, S.M. (2007). Shy children, phobic adults: The nature and treatment of social anxiety disorder (2nd ed.). Washington, DC: American Psychological Association.

Beidel, D., Turner, S., \& Morris, T. (1999). Psychopathology of childhood social phobia. Journal of the American Academy of Adolescent Psychiatry, 38, 643-650.

Binelli, C., Ortiz, A., Muniz, A., Gelabert, E., Ferraz, L., Filho, A., Crippa, J., Nardi, A., Subira, S., \& Martin-Santos, R. (2012). Social anxiety and negative early life events in university students. Revistra Brasileira de Psiquiatria, 34, S69-S80.

Blöte, A., Bokhorst, C., Miers, A., \& Westenberg, P. (2012). Why are socially anxious adolescents rejected by peers? The role of subject-group similarity characteristics. Journal of Research on Adolescence, 22, 123-134. 
Blöte, A., Miers, A., \& Westenberg, P. (2015). The role of social performance and physical attractiveness in peer rejection of socially anxious adolescents. Journal of Research on Adolescence, 25, 189-200.

Bögels, S.M., van Oosten, A., Muris, P., \& Smulders, D. (2001). Familial correlates of social anxiety in children and adolescents. Behaviour Research and Therapy, 39, 273-287.

Bohlin, G., Hagekull, B., \& Rydell, A. (2000). Attachment and social functioning: A longitudinal study from infancy to middle childhood. Social Development, 9, 24-39.

Bosacki, S., Dane, A., Marini, A., \& YLC, CURA. (2007). Peer relationships and internalizing problems in adolescents: Mediating role of self-esteem, Emotional and Behavioural Difficulties, 12, 261-282.

Borelli, J., David, D., Crowley, M., \& Mayes, L. (2010). Links Between disorganized attachment classification and clinical symptoms in school-aged children. Journal of Child and Family Studies, $19,243-256$.

Boulton, M. (2013). Associations between adults' recalled childhood bullying victimization, current social anxiety, coping, and self-blame: Evidence for moderation and indirect effects. Anxiety, Stress, E Coping, 26, 270-292.

Brown, B. (2006). Shame resilience theory: A grounded theory study on women and shame. Families in Society, 87, 43-52.

Bruce, L., Heimberg, R., Blanco, C, Schneier, F., \& Liebowitz, M. (2012). Childhood maltreatment and social anxiety disorder: Implications for symptom severity and response to pharmacotherapy. Depression and Anxiety, 29, 131-138.

Bruce, L., Heimberg, R., Goldin, P., \& Gross, J. (2013). Childhood maltreatment and response to cognitive behavioral therapy among individuals with social anxiety disorder. Depression and Anxiety, 30, 662-669.

Bruch, M. (1989). Familial and developmental antecedents of social phobia: Issues and findings. Clinical Psychology Review, 9, 37-47.

Bruch, M., \& Heimberg, R. (1994). Differences in perceptions of parental and personal characteristics between generalized and nongeneralized social phobics. Journal of Anxiety Disorders, 8, 155-168.

Brumariu, L., \& Kerns, K. (2010). Mother-child attachment patterns and different types of anxiety symptoms: Is there specifitiry of relations? Child Psychiatry and Human Development, 41, 663-674.

Calvete, E., Orue, I., \& Hankin, B. (2013). Early maladaptive schemas and social anxiety in adolescents: The mediating role of anxious automatic thought. Journal of Anxiety Disorders, 27, 278-288.

Carleton, R., Pelso, D., Collimore, K., \& Asmundson, G. (2011). Social anxiety and posttraumatic stress symptoms: The impact of distressing social events. Journal of Anxiety Disorders, 25, 49-57.

Caster, J., Inderbitzen, H., \& Hope, D. (1999). Relationship between youth and parent perceptions of family environment and social anxiety. Journal of Anxiety Disorders, 13, 237-251.

Chartier, M.J., Walker, J.R., \& Stein, M.B. (2001). Social phobia and potential childhood risk factors in a community sample. Psychological Medicine, 31, 307-315.

Claesson, K., \& Sohlberg, S. (2002). Internalized shame and early interactions characterized by indifference, abandonment and rejection: Replicated findings. Clinical Psychology $\mathcal{E}$ Psychotherapy, 9, 277-284.

Clark, D., \& Wells, A. (1995). A cognitive model of social phobia. In R. Heimberg, M. Liebowitz, D. Hope, \& R. Schneier (Eds.), Social phobia: Diagnosis, assessment and treatment (pp. 69-93). New York, NY: Guilford Press.

Cohen, J., \& Kendall, P. (2015). Peer victimization among children and adolescents with anxiety disorders. Child Psychiatry and Human Development, 46, 393-405.

Cougle, J., Timpano, K., Sachs-Ericsson, N., Keough, M., \& Riccardi, C. (2010). Examining the unique relationships between anxiety disorders and childhood physical and sexual abuse in the National Comorbidity Survey-Replication. Psychiatry Research, 177, 150-155.

Craig, W. (1998). The relationship among bullying, victimization, depression, anxiety, and aggression in elementary school children. Personality and Individual Differences, 24 123-130. 
Crome, E., Grove, R., Baillie, A., Sunderland, M., Teesson, M., \& Slade, T. (2015). DSM-IV and DSM-5 social anxiety disorder in the Australian community. Australian and New Zealand Journal of Psychiatry, 49, 227-235.

Dadds, M., Barrett, P., Rapee, R., \& Ryan, S. (1996). Family process and child anxiety and aggression: An observational analysis. Journal of Abnormal Child Psychology, 24 715-733.

DeKlyen, M., \& Greenberg, M. (2008). Attachment and psychopathology in childhood. In: J. Cassidy \& P. Shaver (Eds.), Handbook of attachment (2nd ed., pp. 637-665). New York, NY: Guilford Press.

Demsey, A., \& Storch, E. (2008). Relational victimization: The association between recalled adolescent social experiences and emotional adjustment in early adulthood. Psychology in the Schools, $45,310-322$.

Dinwiddie, S., Heath, A., Dunne, M., Bucholz, K., Madden, P., Slutske, W., Bierut, L., . . Martin, N. (2000). Early sexual abuse and lifetime psychopathology: A co-twin-control study. Psychological Medicine, 30, 41-52.

Eikenaes, I., Pederson, G., \& Wilberg, T. (2015). Attachment styles in patients with avoidant personality disorder compared with social phobia. Psychology and Psychotherapy: Theory, Research and Practice, 89, 245-260.

Elizabeth, J., King, N., Ollendick, T., Gullone, E., Tonge, B., Watson, S., \& Macdermott, S. (2006). Social anxiety disorder in children and youth: A research update on aetiological factors. Counselling Psychology Quarterly, 19, 151-163.

Elzinga, B., Spinhoven, P., Berretty, E., de Jong, P., \& Roelofs, K. (2010). The role of childhood abuse in HPA-axis reactivity in social anxiety disorder: A pilot study. Biological Psychology, 83, $1-6$.

Eng, W., Heimberg, R., Hart, T., Schneier, F., \& Liebowitz, M. (2001). Attachment in individuals with social anxiety disorder: The relationship among adult attachment styles, social anxiety, and depression. Emotion, 1, 365-380.

Erath, S.A., Flanagan, K., \& Bierman, K. (2007). Social anxiety and peer relations in early adolescence: Behavioral and cognitive factors. Journal of Abnormal Child Psychology, 35, 405-416.

Erwin, B., Heimberg, R., Marx, B., \& Franklin, M. (2006). Traumatic and socially stressful life events among persons with social anxiety disorder. Anxiety Disorders, 20, 896-914.

Feerick, M., \& Snow, K. (2005). The relationships between childhood sexual abuse, social anxiety, and symptoms of posttraumatic stress disorder in women. Journal of Family Violence, 20, 409-419.

Fergus, T.A., Valentiner, D.P., McGrath, P.B., \& Jencius, S. (2010). Shame- and guilt-proneness: Relationships with anxiety disorder symptoms in a clinical sample. Journal of Anxiety Disorders, 24, 811-815.

Festa, C., \& Ginsburg, G. (2011). Parental and peer predictors of social anxiety in youth. Child Psychiatry and Human Development, 42, 291-306.

Gazelle, H., Putallaz, M., Li, Y., Grimes, C., Kupersmidt, J., \& Coie, J. (2005). Anxious solitude across contexts: Girls' interactions with familiar and unfamiliar peers. Child Development, 76, 227-246.

Gibb, B., Chelminski, I., \& Zimmerman, M., (2007). Childhood emotional, physical, and sexual abuse, and diagnoses of depressive and anxiety disorders in adult psychiatric outpatients. Depression and Anxiety, 24, 256-263.

Gilbert, P. (2000). The relationship of shame, social anxiety and depression: The role of the evaluation of social rank. Clinical Psychology and Psychotherapy 7, 174-189.

Gilbert, P. (2003). Evolution, social roles and the differences in shame and guilt. Social Research, 70, $1205-1230$.

Gilbert, P. (2014). Evolutionary models: Practical and conceptual utility for the treatment and study of social anxiety disorder. In J. Weeks (Ed.), The Wiley Blackwell handbook of social anxiety disorder (pp. 24-52). Chichester, England: Wiley-Blackwell.

Gilbert, P., Allan, S., \& Goss, K. (1996). Parental representations, shame, interpersonal problems, and vulnerability to psychopathology. Clinical Psychology E Psychotherapy, 3, 23-34. 
Gladstone, G., Parker, G., \& Malhi, G. (2006). Do bullied children become anxious and depressed adults? A cross-sectional investigation of the correlates of bullying and anxious depression. The Journal of Nervous and Mental Disease, 194, 201-208.

Greco, L., \& Morris, T. (2002). Paternal child-rearing style and child social anxiety: Investigation of child perceptions and actual father behavior. Journal of Psychopathology and Behavioral Assessment, 24, 259-267.

Greco, L., \& Morris, T. (2005). Factors influencing the link between social anxiety and peer acceptance: Contributions of social skills and close friendships during middle childhood. Behavior Therapy, 36, 197-205.

Gren-Landell, M., Aho, N., Andersson, G., \& Svedin, C. (2011). Social anxiety disorder and victimization in a community sample of adolescents. Journal of Adolescence, 34, 569-577.

Gulley, L., Oppenheimer, C., \& Hankin, B. (2014). Associations among negative parenting, attention bias to anger, and social anxiety among youth. Developmental Psychology, 50, 577-585.

Hackmann, A., Clark, D., \& McManus, F. (2000). Recurrent images and early memories in social phobia. Behaviour Research and Therapy, 38, 601-610.

Hackmann, A., Surawy, C., \& Clark, D. (1998). Seeing yourself through others' eyes: A study of spontaneously occurring images in social phobia. Behavioural and Cognitive Psychotherapy, 26, $3-12$.

Hedman, E., Strom, P., Stunkel, A., \& Mortberg, E. (2013). Shame and guilt in social anxiety disorder: Effects of cognitive behavior therapy and association with social anxiety and depressive symptoms. PlosOne, 8, 1-8.

Herman, J. (2011). Posttraumatic stress disorder as a shame disorder. In R. Dearing \& J. Tangney (Eds.), Shame in the therapy hour (pp. 261-276). Washington, DC: American Psychological Association.

Higa-McMillan, C., \& Ebesutani, C. (2011). The etiology of social anxiety disorder in adolescents and young adults. In C. Alfano \& D. Beidel (Eds.), Social anxiety in adolescents and young adults: Translating developmental science into practice (pp. 29-51). Washington, DC: American Psychological Association.

Hirsch, C.R., Clark, D.M., Mathews, A., Williams, R., \& Morrison, J. (2006). The causal role of negative imagery in social anxiety: A test in confident public speakers. Journal of Behavior Therapy and Experimental Psychiatry, 37, 159-170.

Hirsch, C., Clark, D., \& Matthews, A. (2006). Imagery and interpretations in social phobia: Support for the combined cognitive biases hypothesis. Behavior Therapy, 37, 223-236.

Hirsch, C., Clark, D., Williams, R., Morrison, J., \& Mathews, A. (2005). Interviewing anxiety: Taking the perspective of a confident other changes inferential processing. Behavioural and Cognitive Psychotherapy, 33, 1-12.

Hirsch, C., Meynen, T., \& Clark, D. (2004). Negative self-imagery in social anxiety contaminates social interactions. Memory, 12, 496-506.

Hirsch, C.., Clark, D., Mathews, A., \& Williams, R. (2003). Self-images play a causal role in social phobia. Behaviour Research and Therapy, 41 (8), 909-921.

Hofmann, S.G., Ehlers, A., \& Roth, W.T. (1995). Conditioning theory: A model for the etiology of public speaking anxiety. Behaviour Research and Therapy, 33, 567-572.

Hudson, J., Comer, J., \& Kendall, P. (2008). Parental responses to positive and negative emotions in anxious and nonanxious children. Journal of Clinical Child $\mathcal{E}$ Adolescent Psychology, 37, 303-313.

Hudson, J., \& Rapee, R. (2000). The origins of social phobia. Behavior Modification, 24, 102-129.

Hudson, J.L., \& Rapee, R. (2001). Parent-child interactions and anxiety disorders: An observational study. Behaviour Research and Therapy, 39, 1411-1427.

Hudson, J.L., \& Rapee, R. (2002). Parent-child interactions in clinically anxious children and their siblings. Journal of Clinical Child and Adolescent Psychology, 31, 548-555.

Hulme, N., Hirsch, C., \& Stopa. (2012). Images of the self and self-esteem: Do positive self-images improve self-esteem in social anxiety? Cognitive Behaviour Therapy, 41, 163-173. 
Hummell, R., \& Gross, A. (2001). Socially anxious children: An observational study of parent-child interaction. Child Eु Family Behavior Therapy, 23, 19-40.

Iffland, B., Sansen, L., Cantani, C., \& Neuner, F. (2012). The trauma of peer abuse: Effects of relational peer victimization and social anxiety disorder on physiological and affective reactions to social exclusion. Frontiers in Psychiatry, 5, 1-9.

Kerns, K., \& Brumariu, L. (2014) Is insecure parent-child attachment a risk factor for the development of anxiety in childhood or adolescence? Child Development Perspectives, 8, 12-17.

Kessler, R.C., Davis, C.G., \& Kendler, K.S. (1997). Childhood adversity and adult psychiatric disorder in the U.S. National Comorbidity Survey. Psychological Medicine 27, 1101-1119.

Kimbrel, N. (2008). A model of the development and maintenance of generalized social phobia. Clinical Psychology Review, 28, 592-612.

Knappe, S., Beesdo, K., Fehm, L., Hofler, M., Leib, R., \& Wittchen, H. (2009). Do parental psychopathology and unfavorable family environment predict the persistence of social phobia? Journal of Anxiety Disorders, 23, 986-994.

Knappe, S., Beeso-Baum, K., Fehm, L., Leib, R., \& Wittchen, H. (2012). Characterizing the association between parenting and adolescent social phobia. Journal of Anxiety Disorders, 26, 608-616.

Knappe, S., Lieb, R., Beesdo, K., Fehm, L., Low, N., Gloster, A., \& Wittchen, H. (2009). The role of parental psychopathology and family environment for social phobia in the first three decades of life. Depression and Anxiety, 26, 363-370.

Kuo, J., Goldin, P., Werner, K., Heimberg, R., \& Gross, J. (2011). Childhood trauma and current psychological functioning in adults with social anxiety disorder. Journal of Anxiety Disorders, 25, $467-473$.

La Greca, A., \& Harrison, H. (2005). Adolescent peer relations, friendships, and romantic relationships: Do they predict social anxiety and depression? Journal of Clinical Child $\mathcal{E}$ Adolescent Psychology, 34, 49-61.

Lampe, L. (2009). Social anxiety disorder: Recent developments in psychological approaches to conceptualization and treatment. Australian and New Zealand Journal of Psychiatry, 43, 887-898

Landoll, R., La Greca, A., Lai, B., Chan, S., \& Herge, W. (2015). Cyber victimization by peers: Prospective associations with adolescent social anxiety and depressive symptoms. Journal of Adolescence, 42, 77-86.

Lee, D., Scragg, P., \& Turner, S. (2001). The role of shame and guilt in traumatic events: A clinical model of shame-based and guilt-based PTSD. British Journal of Medical Psychology, 74, 451-466.

Lee, S., \& Kwon, J., (2013). The efficacy of imagery rescripting (IR) for social phobia: A randomized controlled trial. Journal of Behaviour Therapy and Experimental Psychiatry, 44, 351-360.

Lev-Wiesel, R., \& Sternberg, R. (2012). Victimized at home revictimized by peers: Domestic child abuse a risk factor for social rejection. Child and Adolescent Social Work Journal, 29, 203220.

Lewis, M. (2008). Self-conscious emotions: Embarrassment, pride, shame, and guilt. In M. Lewis, J. Haviland-Jones, \& L. Barrett (Eds.), Handbook of emotions (3rd ed.). New York, NY: Guilford Press.

Lewis-Morrarty, E., Degnan, K., Chronis-Tuscano, A., Rubin, K., Cheah, C., Pine, D., Henderon, H., \& Fox, N. (2012). Maternal over-control moderates the association between early childhood behavioral inhibition and adolescent social anxiety symptoms. Journal of Abnormal Child Psychology, 40, 1363-1373.

Lieb, R., Wittchen, H.U., Hoefler, M., Fuetsch, M., Stein, M.B., \& Merikangas, K.R. (2000). Parental psychopathology, parenting styles, and the risk of social phobia in offspring: A prospectivelongitudinal community study. Archives of General Psychiatry, 57, 859-866.

Lieberman, A., Chu, A., van Horn, P., \& Harris, W. (2011). Trauma in early childhood: Empirical evidence and clinical implications. Development and Psychopathology, 23, 397-410.

Lopez, F., Gover, M., Leskela, J., Sauer, E., Shirmer, L., \& Wyssmann, J. (1997). Attachment styles, shame, guilt, and collaborative problem-solving orientations. Personal Relationships, 4, 187-199. 
Loukas, A., \& Pasch, K. (2013). Does school connectedness buffer the impact of peer victimization on early adolescents' subsequent adjustment problems? The Journal of Adolescence, 33, 245-266.

Magee, W.J. (1999). Effects of negative life experiences on phobia onset. Social Psychiatry and Psychiatric Epidemiology, 34, 343-351.

Majdandzic, M., Moller, E., de Vente, W., Bogels, S., \& van den Boom, D. (2014). Fathers' challenging parenting behavior prevents social anxiety development in their 4-year-old children: A longitudinal observational study. Journal of Abnormal Child Psychology, 42, 301-310.

Marteinsdottir, I., Svensson, A., Svedberg, M., Anderberg, U., \& von Knorring, L. (2007). The role of life events in social phobia. Nordic Journal of Psychiatry, 61, 207-212.

Matos, M., \& Pinto-Gouveia, J. (2010). Shame as a traumatic memory. Clinical Psychology Eु Psychotherapy, 17, 299-312.

Matos, M., Pinto-Gouveia, J., \& Gilbert, P. (2013). The effect of shame and shame memories on paranoid ideation and social anxiety. Clinical Psychology EO Psychotherapy, 20, 334-349.

McCabe, R., Antony, M., Summerfeldt, L., Liss, A., \& Swinson, R. (2003). Preliminary examination of the relationship between anxiety disorders in adults and self-reported history of teasing or bullying experiences. Cognitive Behaviour Therapy, 32, 187-93.

McCabe, R., Miller, J., Laugesen, N., Antony, M., \& Young, L. (2010). The relationship between anxiety disorders in adults an recalled childhood teasing. Journal of Anxiety Disorders, 24, 238-243.

McEvoy, P., Grove, R., \& Slade, T. (2011). Epidemiology of anxiety disorders in the Australian general population: Findings of the 2007 Australian National Survey of Mental Health and Wellbeing. Australian and New Zealand Journal of Psychiatry, 45, 957-967.

McLeod, B., Wood, J., \& Weisz, J. (2007). Examining the association between parenting and childhood anxiety: A meta-analysis. Clinical Psychology Review, 27, 155-172.

Mothander, P., \& Wang, M. (2014). Parental rearing, attachment, and social anxiety in Chinese adolescents. Youth $\mathcal{E}$ Society, 46, 155-175.

Neal, J., \& Edelmann, R. (2003). The etiology of social phobia: Toward a developmental profile. Clinical Psychology Review, 23, 761-786.

Nelson, E., Heath, A., Madden, P., Cooper, M., Dinwiddie, S., Bucholz, K., Glowinski, A., McLaughlin, T., Dunne, M., Statham, D., \& Martin, N. (2002). Association between selfreported childhood sexual abuse and adverse psychosocial outcomes. Archives of General Psychiatry, 59, 139-145.

Nilsson, J., Lundh, L., \& Viborg, G. (2012). Imagery rescripting of early memories in social anxiety disorder: An experimental study. Behaviour Research and Therapy, 50, 387-392.

Norton, A.R., \& Abbott, M.J. (2016). The efficacy of imagery rescripting compared to cognitive restructuring for social anxiety disorder. Journal of Anxiety Disorders, 40, 18-28.

Ollendick, T., \& Hirshfeld Becker, D. (2002). The developmental and psychopathology of social anxiety disorder. Biological Psychiatry, 51, 44-58.

Öst, L. (1987). Age of onset in different phobias. Journal of Abnormal Psychology, 96, 223-229.

Öst, L., \& Hugdahl, K. (1981). Acquisition of phobias and anxiety response patterns in clinical patients. Behaviour Research and Therapy, 19, 439-447.

Pabian, S., \& Vandebosch, H. (2015). An investigation of short-term longitudinal associations between social anxiety and victimization and perpetration of traditional bullying and cyberbullying. Journal of Youth and Adolescence, 45, 328-339.

Parker, G. (1979). Reported parental characteristics of agoraphobics and social phobics. The British Journal of Psychiatry, 135, 555-560.

Pechtel, P., Lyons-Ruth, K., Anderson, C., \& Teicher, M. (2014). Sensitive periods of amygdala development: The role of maltreatment in preadolescence. NeuroImage, 97, 236-244.

Pinto-Gouveia, J., \& Matos, M. (2011). Can shame memories become a key to identity? The centrality of shame memories predicts psychopathology. Applied Cognitive Psychology, 25, 281-290.

Pinto-Gouveia, J., Gastilho, P., Galhardo, A., \& Cunha, M. (2006). Early maladaptive schemas and social phobia. Cognitive Therapy and Research, 30, 571-584. 
Pohjavaara, P (2004). Social phobia: Aetiology, course and treatment with endoscopic sympathetic block (ESB) (Unpublished doctoral dissertation). University of Oulu, Finland.

Ranta, K., Kaltiala-Heino, R., Frojd, S., \& Marttunen, M. (2013). Peer victimization and social phobia: A follow-up study among adolescents. Social Psychiatry and Psychiatric Epidemiology, 48, 533-544.

Ranta, K., Kaltiala-Heino, R., Pelkonen, M., \& Marttunen, M. (2009). Associations between peer victimization, self-reported depression and social phobia among adolescents: the role of comorbidity. Journal of Adolescence, 32, 77-93.

Rapee, R., \& Heimberg, R. (1997). A cognitive-behavioral model of anxiety in social phobia. Behaviour Research and Therapy, 35, 741-756.

Rapee, R.M., \& Melville, L.F. (1997). Retrospective recall of family factors in social phobia and panic disorder. Depression and Anxiety, 5, 7-11.

Rapee, R., \& Spence, S. (2004). The etiology of social phobia: Empirical evidence and an initial model. Clinical Psychology Review, 24, 737-767.

Reimer, S., \& Moscovitch, D. (2015). The impact of imagery rescripting on memory appraisals and core beliefs in social anxiety disorder. Behaviour Research and Therapy, 75, 48-59.

Rork, K., \& Morris, T. (2009). Influence of parenting factors on childhood social anxiety: Direct observation of parental warmth and control. Child $\mathcal{E}$ Family Behavior Therapy, 31, 220-235.

Rosellini, A., Rutter, L., Bourgeois, M., Emmert-Aronson, B., \& Brown, T. (2013). The relevance of age of onset to the psychopathology of social phobia. Journal of Psychopathology and Behavioural Assessment, 35, 356-365.

Roth, D., Coles, M., \& Heimberg, R. (2002). The relationship between memories for childhood teasing and anxiety and depression in adulthood. Journal of Anxiety Disorders, 16, 149-164.

Rubin, K., \& Mills, R. (1988). The many faces of social isolation in childhood. Journal of Consulting and Clinical Psychology, 56, 916-924.

Rudoph, J., \& Zimmer-Gembeck, M. (2014). Parent relationships and adolescents' depression and social anxiety: Indirect associations via emotional sensitivity to rejection threat. Australian Journal of Psychology, 66, 110-121.

Ruscio, A., Brown, T., Chiu, W., Sareen, J., Stein, M., \& Kessler, R. (2008). Social fears and social phobia in the usa: results from the national comorbidity survey replication. Psychological Medicine, $38,15-28$.

Safren, S., Gershuny, B., Marzol, P., Otto, M., \& Pollack, M. (2002). History of childhood abuse in panic disorder, social phobia, and generalized anxiety disorder. The Journal of Nervous and Mental Disease, 190, 453-456.

Sansen, L., Iffland, B., \& Neuner, F. (2015). The trauma of peer victimization: Psychophysiological and emotional characteristics of memory imagery in subjects with social anxiety disorder. Psychophysiology, 52, 107-116.

Scaini, S., Belotti, R., \& Ogliari, A. (2014). Genetic and environmental contributions to social anxiety acrossdifferent ages: A meta-analytic approach to twin data. Journal of Anxiety Disorders, 28, 650-656.

Scharfstein, L., Alfano, C., Beidel, B., \& Wong, N. (2011). Children with generalized anxiety disorder do not have peer problems, just fewer friends. Child Psychiatry and Human Development, $42,712-723$.

Schreiber, F., \& Steil, R. (2013). Haunting self-images? The role of negative self-images in adolescent social anxiety disorder. Journal of Behavior Therapy and Experimental Psychiatry, 44, 158-164.

Shahar, B., Doron, G., \& Szepsenwol, O. (2014). Childhood maltreatment, shame-proneness and self-criticism in social anxiety disorder: A sequential mediational model. Clinical Psychology and Psychotherapy, 22, 570-579.

Siegel, R., La Greca, A., \& Harrison, H. (2009). Peer victimization and social anxiety in adolescents: prospective and reciprocal relationships. Journal of Youth and Adolescence, 38, 1096-1109. 
Simon, N., Herlands, N., Marks, E., Mancini, C., Letamendi, A., Zhonghe, L., ... Stein, M. (2009). Childhood maltreatment linked to greater symptom severity and poorer quality of life and function in social anxiety disorder. Depression and Anxiety, 26, 1027-1032.

Spinhoven, P., Elzinga, B., Hovens, J., Roelofs, K., Zitma, F., van Oppen, P., \& Penninx, B. (2010). The specificity of childhood adversities and negative life events across the life span to anxiety and depressive disorders. Journal of Affective Disorders, 126, 103-112.

Spokas, M., \& Heimberg, R. (2009). Overprotective parenting, social anxiety, and external locus of control: Cross-sectional and longitudinal relationships. Cognitive Therapy and Research, 33, $543-551$.

Stein, D., Ono, Y., Tajima, O., \& Muller, J. (2004). The social anxiety disorder spectrum. Journal of Clinical Psychiatry, 65(Suppl. 14), 27-33.

Stein, M., Walker, J., Anderson, G., Hazen, A., Ross, C., Eldridge, G., \& Forde, D. (1996). Childhood physical and sexual abuse in patients with anxiety disorders and in a community sample. American Journal of Psychiatry, 153, 275277.

Stemberger, R.T., Turner, S.M., Beidel, D.C., \& Calhoun, K.S. (1995). Social phobia: An analysis of possible developmental factors. Journal of Abnormal Psychology, 104, 526-531.

Stopa, L., \& Jenkins, A. (2007). Images of the self in social anxiety: Effects on the retrieval of autobiographical memories. Journal of Behavior Therapy and Experimental Psychiatry, 38, 459-473.

Storch, E., Brassard, M., \& Masia-Werner, C. (2003). The relationship of peer victimization to social anxiety and loneliness in adolescence. Child Study Journal, 33, 1-18.

Storch, E., \& Masia-Warner, C. (2004). The relationship of peer victimization to social anxiety and loneliness in adolescent females. Journal of Adolescence, 27, 351-362.

Storch, E., Masia-Werner, C., Crisp, H., \& Klein, R. (2005). Peer victimization and social anxiety in adolescence: A prospective study. Aggressive Behavior, 31, 437-452.

Stuewig, J., \& McCloskey, L. (2005). The relation of child maltreatment to shame and guilt among adolescents: psychological routes to depression and delinquency. Child Maltreatment, 10, 324336.

Taylor, C., \& Alden, L. (2006). Parental overprotection and interpersonal behavior in generalized social phobia. Behavior Therapy, 37, 14-24.

Teachman, B., \& Allen, J. (2007). Development of social anxiety: Social interaction predictors of implicit and explicit fear of negative evaluation. Journal of Abnormal Child Psychology, 35, 63-78.

Tiet, Q., Bird, H., Hoven, C., Moore, R., Wu, P., Wicks, J., Jensen, P., Goodman, S., \& Cohen, P. (2001). Relationship between specific adverse life events and psychiatric disorders. Journal of Abnormal Child Psychology, 29, 153-164.

Tillfors, M. (2004). Why do some individuals develop social phobia? A review with emphasis on the neurobiological influences. Nordic Journal of Psychiatry, 58, 267-276.

Tillfors, M., Persson, S., Willen, M., \& Burk, W. (2012). Prospective links between social anxiety and adolescent peer relations. Journal of Adolescence, 35, 1255-1263.

Vernberg, E., Abwender, D., Ewell, K., \& Beery, S. (1992). Social anxiety and peer relationships in early adolescence. A prospective analysis. Journal of Clinical Child Psychology, 21, 189-196.

Vertue, F. (2003). From adaptive emotion to dysfunction: An attachment perspective on social anxiety disorder. Personality and Social Psychology Review, 7, 170-191.

Vreeke, L., Muris, P., Mayer, B., Huijding, J., \& Rapee, R. (2013). Skittish, shielded, and scared: Relations among behavioral inhibition, overprotective parenting, and anxiety in native and non-native Dutch preschool children. Journal of Anxiety Disorders, 27, 703-710.

Warren, S., Huston, L., Egeland, B., \& Sroufe, A. (1997). Child and adolescent anxiety disorders and early attachment. Journal of the American Academy of Child and Adolescent Psychiatry, 36, 637-644.

Webb, M., Heisler, D., Call, S., Chickering, S., \& Colburn, T. (2007). Shame, guilt, symptoms of depression, and reported history of psychological maltreatment. Child Abuse $\mathcal{E}$ Neglect, 31, 1143-1153. 
Wild, J. (2009). Imagery and the self in social phobia. In L. Stopa (Ed.), Imagery and the threatened self. (pp. 94-111). New York, NY: Routledge.

Wild, J., Hackmann, A., \& Clark, D.M. (2008). Rescripting early memories linked to negative images in social phobia: A pilot study. Behavior Therapy, 39, 47-56.

Wilson, J., \& Rapee, R. (2006). Self-concept certainty in social phobia. Behaviour Research and Therapy, 44, 113-136.

Wong, Q., \& Rapee, R. (2015). The Developmental Psychopathology of social anxiety and phobia in adolescents. In K. Ranta, A. La Greca, \& L. Garcia-Lopz (Eds.), Social anxiety and phobia in adolescents: Development, manifestation and intervention strategies (pp. 11-37). Cham, Switzerland: Springer International Publishing.

Woodruff-Borden, J., Morrow, C., Bourland, S., \& Cambron, S. (2014). The behavior of anxious parents: examining mechanisms of transmission of anxiety from parent to child. Journal of Clinical Child E Adolescent Psychology, 31, 364-374.

Yen, C., Yang, P., Wang, P., Lin, H., Liu, T., Wu, Y., Tang, T. (2014). Association between school bullying levels/types and mental health problems among Taiwanese adolescents. Comprehensive Psychiatry, 55, 405-413.

Young, J. (1999). Cognitive therapy for personality disorders: A schema-focused approach (3rd ed.). Sarasota, FL: Professional Resource Exchange. 